\title{
Diferenças semânticas e coerência matemática: introdução aos problemas de congruência ${ }^{1}$
}

Raymond Duval

\author{
Professor Emérito da Université du Littoral Côte d'Opale/France
}

Tradução: Méricles Thadeu Moretti

PPGECT/MTM/UFSC

mericles@mtm.ufsc.br

\begin{abstract}
Resumo
Substituir uma expressão ou uma representação por outra, que lhe é referencialmente equivalente, é central na atividade matemática. Diferentemente do funcionamento natural do pensamento, este processo de substituição não se situa na semelhança entre o conteúdo da expressão ou representação dada e o conteúdo da expressão que substituímos para resolver um dado problema. Esta substituição constitui em um percalço. Passa-se de uma frase para uma expressão simbólica, de uma representação gráfica para uma expressão simbólica ou de uma figura a outra que é de toda diferente. Em certos casos, entre os conteúdos a serem substituídos, existe uma correspondência direta e fácil de ser reconhecida. Para caracterizar esta situação cognitiva, falamos de congruência semântica. Mas, na maioria dos casos, não há alguma relação de correspondência direta e os conteúdos parecem ser estranhos ou irreconhecíveis. Neste caso, falamos de não congruência semântica. É a situação cognitiva de toda atividade matemática. Este artigo, chamará a atenção, inicialmente, para a não congruência semântica que origina custos cognitivos importantes em atividades evidentes na determinação da posição de dois objetos, um em relação ao outro. As dificuldades matemáticas para reconhecer e compreender o processo de substituição por equivalência referencial, vêm, inicialmente, da não congruência semântica. Será realizada uma análise sobre uma gama de problemas elementares, que utilizam conhecimentos matemáticos bastante diferentes, em que sistematicamente os alunos têm dificuldades em resolvê-los e são bem conhecidos pelos professores. Para finalizar, serão abordadas duas questões essenciais que traz à tona a diferença entre o funcionamento natural do pensamento e a maneira que é própria dos matemáticos. Como descrever o funcionamento cognitivo dos matemáticos? Isto é crucial para tornar os alunos capazes de compreender a matemática, uma vez que a não congruência semântica não está relacionada a alguma dificuldade conceitual e que o processo de substituição, por equivalência, não é uma codificação ${ }^{2}$. Em função de quais objetivos prioritários o ensino de matemática deve ser organizado?
\end{abstract}

\footnotetext{
${ }^{1}$ N. T. Este texto é uma tradução do artigo: DUVAL, R. Écarts sémantiques et cohérence mathématique: introduction aux problèmes de congruence. Annales de Didactique et de Sciences Cognitives, v.1, p. 7-25, Strasbourg: ULP - IREM, 1988. Algumas adaptações de forma no texto original foram produzidas para adequar às normas da $\mathrm{ABNT}$, além de um novo resumo e precisões feitas pelo autor.

${ }^{2}$ Nas publicações seguintes eu desenvolvi um modelo de funcionamento cognitivo para analisar a complexidade de todos esses processos e produções que surgem. A descrição de diferentes registros de representação semiótica permite introduzir a distinção que é fundamental entre conversão e tratamento. E é por isso que após este
} 


\title{
Résumé
}

Substituer une expression, ou une représentation, à une autre qui lui est référentiellement équivalente est au cœur de l'activité mathématique. A la différence de fonctionnement naturel de la pensée, ce processus de substitution ne repose sur aucune ressemblance entre les contenus de l'expression ou de la représentation donnée et de celle qu'on y substitue pour pouvoir résoudre un problème. Elle constitue un saut. On passe d'une phrase à une expression symbolique, d'une représentation graphique à une expression symbolique ou d'une figure à une autre qui est toute différente. Dans certains cas, entre les deux contenus à substituer, il y a des mises en correspondances directes et faciles à reconnaître. Pour caractériser cette situation cognitive nous parlerons de congruence sémantique. Mais dans la plupart des cas, il n'y a aucune mise en correspondance directe et les deux contenus semblent s'opposer ou diverger. Nous parlerons alors de non congruence sémantique. C'est la situation cognitive de toute activité mathématique.

Dans ce papier nous rappellerons d'abord que la non congruence sémantique entraîne des coûts cognitifs importants dans une tâche évidente de vérification de la position de deux éléments l'un par rapport à l'autre. Les difficultés dans l'apprentissage des mathématiques à reconnaître et à comprendre le processus de substitution par équivalence référentielle viennent d'abord de la non congruence sémantique. Nous analyserons une gamme de problèmes élémentaires qui font appel à des connaissances mathématiques très différentes. Ils donnent tous lieu à des échecs systématiques et récurrents qui sont bien connus par les enseignants. Pour finir nous aborderons les deux questions essentielles que soulève cet écart entre le fonctionnement naturel de la pensée et la manière de pensée propre aux mathématiques. Comment décrire le fonctionnement cognitif propre aux mathématiques? Car cela est crucial pour rendre les élèves capable de comprendre les mathématiques, puisque la non congruence sémantique n'est aucunement liée à une difficulté conceptuelle et que le processus de substitution par équivalence référentielle n'est pas un codage ${ }^{3}$. En fonction de quels objectifs prioritaires un enseignement des mathématiques pour tous les élèves doit-il être organisé?

\begin{abstract}
Substituting an expression or representation to another, which is referentially equivalent, is the core of mathematical activity. Unlike the natural functioning of thinking, this substitution process does not based on any similarity between the content of the expression or representation given and the one by which it has to be replaced in order to solve a problem. It is the jump from one sentence to a symbolic expression or graph to symbolic expression or figure to another that looks quite different. In some cases, between the two contents to be substituted, there are direct mappings easy to recognize. We call this cognitive situation semantic congruence. But in most of the cases, there is no direct mapping and both contents are opposing or diverging. We then call this cognitive situation semantic non-congruence. It is the cognitive situation in which any mathematical activity runs.

In this paper, we first show that semantic non-congruence leads to significant cognitive costs in the most obvious task of checking the position of two elements one relative to the other. Most troubles in mathematics learning to recognize and understand the process of substitution by referential equivalence stem first of all from semantic non-congruence. We analyze a range of elementary tasks and problems about quite different mathematical knowledge, which all lead to systematic and recurrent failures well known by teachers. Finally we discuss the two issues that this gap between the natural functioning of thinking and the way of thinking specific to mathematics raises. How to describe the cognitive functioning specific to mathematics? Because it is crucial to make students able to understand mathematics, since the semantic non-congruence is not at all related to a conceptual difficulty and the process by referential substitution is not an encoding ${ }^{4}$. According to which priority goals mathematics education for all pupils should be organized?
\end{abstract}

primeiro artigo, eu não mais falei de congruência semântica e de não congruência semântica, mas somente de fatores de congruência e não congruência na conversão de representações.

${ }^{3}$ Dans les publications suivantes j'ai développé un modèle de fonctionnement cognitif pour analyser la complexité de tous ces processus et des productions auxquelles elles donnent lieu. La description des différents registres de représentation sémiotique permet d'introduire la distinction fondamentale entre conversion et traitement. C'est pourquoi après ce tout premier article je n'ai plus parlé de congruence sémantique et de non congruence sémantique, mais seulement des facteurs de congruence et de non congruence dans la conversion des représentations.

${ }^{4}$ In the later publications I have developed a model of cognitive functioning to analyze the complexity of all these processes and productions to which they give rise. The description of the various registers of semiotic representation allows the introduction of the fundamental distinction between conversion and treatment. That is why after this first paper, I no longer spoke of semantic congruence and no congruence, but only factors of congruence and non-congruence in the conversion of representations. 


\section{Introdução}

Substituir uma formulação ou uma apresentação por outra, referencialmente equivalente, é um processo essencial para o pensamento matemático. E esta substituição, em geral, exige algumas condições para que haja sentido no pensamento natural: a continuidade semântica e a associatividade entre as expressões a serem substituídas. A distinção, por tudo isto que é considerado como referencialmente equivalente, entre uma relação de congruência semântica e uma relação de não congruência, comanda o problema da significação em matemática: ela é corroborada por uma variação importante de custo no tratamento cognitivo. Certas dificuldades de aprendizagem matemática, aparentemente heterogêneas, encontram nesta perspectiva uma interpretação precisa e fecunda.

A distinção entre sentido e referência, Sinn e Bedeutung, mostrou-se ser uma das mais fecundas em todos os domínios nos quais à relação aos conceitos e às ideias efetuam-se por meio da manipulação de signos, de símbolos ou de expressões. (FREGE, 1971). Esta distinção induziu a separar com clareza a significação, que depende do registro de descrição escolhida, da referência que depende dos objetos expressos ou representados. Por exemplo, 4/2, (1+1) e $\sqrt{4}$ são formas escritas que designam um mesmo número, quer dizer, são expressões que fazem referência a um mesmo objeto. Mas, não possuem o mesmo significado, uma vez que não são reveladores do mesmo domínio de descrição ou do mesmo ponto de vista: a primeira exprime o número em função de propriedades de divisibilidade e razão, a segunda em função da recorrência à unidade. Uma simples mudança na escrita é suficiente para exibir propriedades diferentes do objeto, mesmo se for mantida a mesma referência. A distinção entre sentido e referência está estreitamente ligada ao princípio de substituição, que é essencial nos procedimentos de cálculo ou de dedução: duas expressões, com a mesma referência, podem ser trocadas uma pela outra, em uma frase ou em uma fórmula, sem que o valor da verdade mude.

A distinção introduzida por Frege (1971) teve, por efeito, privilegiar o sentido referencial em detrimento do que será denominado o sentido associativo interno (a um domínio, a um registro, a uma teoria ou a um contexto). Isto era normal, uma vez que a noção de referência assim desprendida, levantava novas questões sobre as quais logicistas e linguistas longamente estudaram. (QUINE, 1977; DUCROT, 1972). No entanto, isto desviou a atenção de um problema fundamental: a possibilidade cognitiva da substituição entre duas expressões referencialmente equivalentes. Esta substituição constitui, geralmente, para os indivíduos em situação de aprendizagem ou mesmo em pesquisa, um salto entre duas redes semânticas, a 
tal ponto que os próprios indivíduos não se dão conta e, mesmo quando indicada, lhes parece arbitrária. Em outros termos, do ponto de vista da constituição objetiva do saber, a substituição, que permite desenvolver o cálculo e a demonstração, funciona em relação à referência. Mas, do ponto de vista da apropriação subjetiva do saber matemático, a substituição funciona primeiramente em relação ao sentido associativo interno: tudo depende, então, daquilo que chamaremos de congruência ou não congruência semântica das expressões a serem substituídas uma pela outra. Duas expressões podem ser sinônimas ou referencialmente equivalentes (elas podem "querer dizer a mesma coisa", elas podem ser verdadeiras ou falsas ao mesmo tempo) e não serem semanticamente congruentes: neste caso, há um custo cognitivo importante para a compreensão.

Entre duas expressões, duas apresentações de uma informação, há duas relações independentes a serem consideradas: a relação de equivalência referencial e a relação de congruência semântica. Duas expressões diferentes podem ser referencialmente equivalentes sem que sejam semanticamente congruentes. Inversamente, duas expressões podem ser semanticamente congruentes sem que sejam referencialmente equivalentes. Alguns exemplos serão apontados mais adiante.

O matemático examina, prioritariamente, a equivalência referencial. Tal procedimento, em geral, vai ao encontro de uma condição necessária para que haja sentido no pensamento natural: a continuidade semântica e associativa entre as expressões a serem substituídas. Um aluno que não se dá conta do esforço intelectual exigido em matemática faz, espontaneamente da congruência semântica, a condição necessária e às vezes suficiente da equivalência referencial. Ele encontrará e ficará satisfeito com as substituições que são semanticamente congruentes; por outro lado, ele irá resistir às substituições que não são semanticamente congruentes, mas referencialmente equivalentes. A matemática, excluindo o cálculo aritmético elementar, mostra-se geralmente mais arbitrária do que "lógica".

A substitutividade de expressões é uma propriedade inerente a todo registro semiótico que apresenta uma ideia ou informação. Ela permite, por exemplo, o desenvolvimento do discurso no plano da linguagem natural: o emprego de termos sinonímicos, a possibilidade de paráfrase são modos de funcionamento. Mas, esta substitutividade é também essencial em toda mudança de registro semiótico. Ora em matemática, mais do que em qualquer outra disciplina, estas mudanças são, ao mesmo tempo, importantes e frequentes. Basta abrir qualquer manual escolar de qualquer nível para ver, em uma mesma página, a passagem de uma frase para uma fórmula aritmética ou algébrica, a passagem de um enunciado para uma 
figura geométrica, ou a passagem da escrita algébrica para o gráfico. A conduta em matemática implica uma substitutividade tanto inter-registro quanto intra-registro com base na invariabilidade da referência. Afora a relação de ilustração entre um texto e uma figura, relação geralmente admitida como evidente e imediata, estas mudanças de registros obedecem a certos procedimentos elementares de codificação para passar, por exemplo, da escrita simbólica para a representação gráfica e também para efetuar a passagem inversa do registro gráfico para o registro discursivo ou algébrico. Aqui, também, a substitutividade se depara com dificuldades relacionadas à diferenças semânticas, apesar da aparente simplicidade das regras de correspondência entre registros.

Um dos obstáculos encontrados por muitos alunos na aprendizagem de matemática está ligado ao fato de que a equivalência referencial destaca-se da congruência semântica e, no entanto, o funcionamento espontâneo do pensamento segue prioritariamente a congruência semântica. A substituição de uma expressão, que pertence a uma rede semântica, para uma expressão de outra rede semântica, se apresenta, às vezes, como um salto dificilmente transponível. É a especificidade deste tipo de dificuldade que iremos evidenciar. Para isto, serão apresentadas, inicialmente, algumas experiências psicológicas que mostraram a existência deste fenômeno de congruência semântica; em seguida, sucintamente alguns exemplos em matemática.

\section{Custo da não congruência em tarefas de constatação ou de verificação}

Experiências em situações elementares de comparação entre imagem e frase que descreve esta imagem evidenciaram a variação do tempo de reação, quando a imagem e o enunciado são ou não congruentes. (CLARK e CHASE, 1972).

A posição de dois objetos $\mathrm{A}$ e $\mathrm{B}$, um em relação ao outro, pode ser apresentada conforme o modo indicado na figura a seguir. 
Figura 1 - apresentação icônica e discursiva de dois objetos A e B.

\begin{tabular}{|c|c|}
\hline $\begin{array}{c}\text { Iconicamente } \\
\text { A }\end{array}$ & Discursivamente \\
B & A está acima de B \\
& B está abaixo de A \\
\hline
\end{tabular}

Limitando-se à imagem acima, é possível observar logo que temos quatro enunciados diferentes para expressar a mesma situação dada pela imagem: dois enunciados mencionados à direita da imagem (A está acima de $\mathrm{B}$ e $\mathrm{B}$ está abaixo de $\mathrm{A}$ ) e dois enunciados negando os recíprocos (B não está acima de A e A não está abaixo de B). Considerando, também, que estes quatro enunciados devem ser diferenciados de outros quatro enunciados falsos: A está abaixo de B, etc. Duas questões impõem-se:

- o reconhecimento da equivalência referencial ou da não equivalência referencial entre a apresentação icônica e a apresentação discursiva, tem um mesmo custo para cada uma das oito expressões?

- os sentidos que orientam as comparações da imagem para a frase ou da frase para a imagem podem ser desprezados?

Admitindo que o tratamento da apresentação icônica e o da apresentação discursiva passam por uma codificação proposicional interna, a comparação entre imagem e frase é, de fato, a comparação de duas sequências internas respectivas. Então, dois casos apresentam-se:

Caso 1: os elementos das duas sequências internas podem ser comparados termo a termo a menos de uma pequena diferença: elas explicitam as mesmas unidades de informação na mesma ordem. Uma decisão de equivalência referencial só pode ser tomada se não há diferença alguma e, mesmo que haja uma só diferença, a decisão de não equivalência referencial se impõe. Consequentemente, duas sequências que não apresentam a mesma ordem ou que apresentam mais de uma unidade de informação diferente, não podem ter os seus elementos comparáveis termo a termo. 
Caso 2: os elementos das duas sequências não podem ser comparados termo a termo, mesmo com uma pequena diferença, porque elas não explicitam as mesmas unidades ou porque a ordem não corresponde: é preciso, então, proceder a uma transformação, de uma das duas sequências, para torná-las comparáveis.

No Caso 1, as duas apresentações, imagem e enunciado, são ditas congruentes. No Caso 2, as duas apresentações não são congruentes. Duas apresentações podem ser ditas mais ou menos congruentes, segundo o número de transformações necessárias para tornar as suas sequências internas comparáveis termo a termo.

No exemplo acima, temos, para os oito enunciados, três variações possíveis para codificar a relação entre A e B:

- uma variação de traço semântico: acima de, abaixo de;

- uma variação do ponto de referência: A sujeito, B sujeito;

- uma variação de forma: afirmação, negação $(\sim)$.

Tabela 1 - Oito enunciados possíveis, verdadeiros ou falsos, relativos à imagem codificada “A está acima de B".

\begin{tabular}{|c|c|c|c|c|c|c|c|}
\hline & \multicolumn{3}{|c|}{ Forma positiva } & \multicolumn{3}{|c|}{ Forma negativa $(\sim)$} \\
\hline & & Seq. interna & Tempo & Valor & Seq. interna & Tempo & Valor \\
\hline \multirow{2}{*}{$\begin{array}{c}\text { A } \\
\text { mesma } \\
\text { ordem }\end{array}$} & $\begin{array}{c}\text { O mesmo } \\
\text { traço } \\
\text { semântico }\end{array}$ & $\begin{array}{l}\text { A está acima de B } \\
\text { (1) }\end{array}$ & 1783 & V & $\begin{array}{c}\text { (A está acima de B }) \\
\mathbf{( 5 )}\end{array}$ & 2354 & $\mathrm{~F}$ \\
\hline & $\begin{array}{c}\text { Traço } \\
\text { antonímico }\end{array}$ & $\begin{array}{l}\text { A está abaixo de } \\
\text { B (2) }\end{array}$ & 2077 & $\mathrm{~F}$ & $\begin{array}{c}\text { (A está abaixo de B) } \\
(\mathbf{6})\end{array}$ & 2499 & $\mathrm{~V}$ \\
\hline \multirow{2}{*}{$\begin{array}{l}\text { Ordem } \\
\text { inversa }\end{array}$} & $\begin{array}{l}\text { O mesmo } \\
\text { traço } \\
\text { semântico }\end{array}$ & $\begin{array}{l}\text { B está acima de A } \\
\text { (3) }\end{array}$ & 2130 & $\mathrm{~F}$ & $\begin{array}{c}\sim(\text { B está acima de } \mathrm{A}) \\
\mathbf{( 7 )}\end{array}$ & 2614 & $\mathrm{~V}$ \\
\hline & $\begin{array}{c}\text { Traço } \\
\text { antonímico }\end{array}$ & $\begin{array}{l}\text { B está abaixo de } \\
\text { A (4) }\end{array}$ & 2139 & $\mathrm{~V}$ & $\underset{(\mathbf{8})}{\sim(\text { B está abaixo de A) }}$ & 2678 & $\mathrm{~F}$ \\
\hline
\end{tabular}

Os tempos indicados na Tabela 1 são as médias, em milissegundos de tempo de reação, registrados por Clark e Chase (1972). 
Examinando esta tabela, pode-se constatar que:

- a frase que tem o (1) (A está acima de B) como sequência interna é congruente à imagem: o reconhecimento da equivalência referencial toma nitidamente menos tempo do que no caso das outras frases;

- a frase que tem o (2) (A está abaixo de B) por sequência interna, é mais congruente com a imagem do que a frase que tem o (4) (B está abaixo de A) por sequência interna, se bem que esta última é referencialmente equivalente à imagem: assim, embora (2) não seja referencialmente congruente com a imagem, ela é mais rapidamente tratada do que a frase (4) que é referencialmente congruente com a imagem.

A diferença entre a sequência (1) e (2) pode ser explicada, segundo o modelo de tratamento proposto por Clark, por um custo maior para constatar algo que é falso de algo que é verdadeiro. Sob esta hipótese, as frases tendo por sequência (1) e (2) são, deste modo, igualmente congruentes: elas podem ser diretamente comparadas termo a termo com a imagem a menos de uma pequena diferença. Vê-se, aliás, que estas frases tomam menos tempo do que todas as outras, em uma atividade de verificação, ainda que uma seja verdadeira (1) e a outra falsa (2);

- as quatro frases referencialmente equivalentes (valor V) apresentam, de um ponto de vista cognitivo, diferenças semânticas, em que o custo varia com o grau da não congruência.

Não é apenas na situação de comparação entre imagem e frase que o fenômeno de congruência semântica tem um papel importante, mas também no interior de um mesmo registro e, mais particularmente, nos discurso natural. Isto aparece de modo particularmente claro no caso de resposta a uma questão solicitada em problema. Se a formulação da questão é congruente com a formulação das informações dadas no enunciado do problema e, se esta formulação também é congruente com uma formulação possível da resposta, esta resposta será mais rápida, desde que não seja um caso de não congruência. Este fenômeno foi evidenciado por Clark (1969) em problemas a três termos. Estes problemas tornaram-se clássicos porque eles faziam parte de uma bateria de testes de inteligência no começo do século XX e também porque foram retomados por Jean Piaget que pôde, a partir destes testes, afirmar a prioridade da ação sobre a linguagem no desenvolvimento da 
inteligência lógica. (PIAGET, p. 7 - 9, 75, 76). Clark (1969) retomou este tipo de problema variando sistematicamente a formulação:

A é melhor do que $\mathrm{B}, \mathrm{B}$ é melhor do que $\mathrm{C}$, qual é o melhor?

A é melhor do que $\mathrm{B}, \mathrm{B}$ é melhor do que $\mathrm{C}$, qual é o pior?

A é pior ...

A leitura das médias geométricas dos tempos de reação, mostra que a resposta é mais rápida quando a questão (qual é o melhor?, qual é o pior?) é congruente com a segunda proposição do enunciado do que quando ela não o é; em seguida, quando as duas proposições do enunciado são congruentes entre si. (CLARK, 1969). Estes resultados são interessantes, uma vez que se comparam à diferença que há entre os acertos às provas de seriação (ou ordenação) e os acertos aos problemas a três termos. Contrariamente a que Piaget supôs para justificar a prioridade da ação sobre a linguagem, as duas atividades não têm a mesma natureza: existem dificuldades cognitivas relativas ao discurso natural e, algo que não se pode desprezar, estas dificuldades dizem respeito a não congruência semântica entre expressões referencialmente equivalentes. Os problemas a três termos são cognitivamente mais complexos do que as provas de seriação.

O problema da congruência ou da não congruência semântica de duas apresentações de um mesmo objeto é, portanto, o da distância cognitiva entre estas duas representações, sejam elas pertencentes ou não ao mesmo registro. Quanto maior a distância cognitiva, mais o custo da passagem de uma apresentação a outra corre o risco de ser elevado, e também de não ser efetuado ou entendido. Em outras palavras: a equivalência referencial não é uma razão suficiente para reunir em uma mesma rede semântica e, a fortiori, para assegurar a evidência imediata da substituição de uma expressão por outra não congruente. Esta dificuldade é encontrada pela maioria dos alunos em diferentes níveis e em diferentes domínios da aprendizagem matemática, e torna-se ainda mais importante porque não é explicitamente e sistematicamente levada em conta.

\section{Alcance da não congruência semântica em matemática}

Para mostrar a importância da não congruência na aprendizagem matemática, três exemplos bastante conhecidos serão levados em consideração. O primeiro refere-se a passagem entre a 
representação geométrica da reta e a representação simbólica dos números reais (na escrita decimal, na escrita fracionária, nos procedimentos de encaixamento de intervalos, etc). $\mathrm{O}$ segundo exemplo está relacionado ao discurso natural na compreensão de enunciados de problemas. O terceiro trata da passagem do enunciado de uma relação matemática para a escrita algébrica desta relação.

\section{III.1. A não congruência semântica entre o traçado de uma reta e o conjunto dos números reais.}

Para o matemático, um dos interesses da reta é dar uma representação do contínuo, propriedade específica do conjunto dos reais, em relação ao conjunto dos racionais, que é somente denso. Pela característica discreta e individualizante, as escritas decimais e fracionárias dos números reais tendem a ocultar esta propriedade de continuidade: as regras que geram a escrita dos números permitem não mais do que "realizar" algoritmicamente a densidade. Como passamos no ensino do registro simbólico de escrita, registro por excelência de manipulação de números, ao registro figurativo da reta? É de fato difícil falar no ensino de "reta numérica" sem fazer referência, de fato, à representação figurativa de uma reta.

Esta passagem se efetua pela noção de "ponto". A reta é interpretada como um "conjunto infinito de pontos" (conjunto infinito que tem a potência do contínuo) e este conjunto está em bijeção com o conjunto dos números reais: a cada ponto da reta corresponde um número real e vice versa. Ora, é justamente esta noção de ponto que causa problema: um conjunto de pontos sobre um registro figurativo é discreto, não pode ser contínuo. De fato:

- a figura de uma reta é estranha a toda representação do ponto: seu traçado é gerado por um movimento e a propriedade de continuidade depende desta representação dinâmica (no sentido físico);

- a figura de um ponto mostra um outro processo de representação diferente de uma reta: ela é a marca de uma pura localização, resultado de uma visão dêitica ou do cruzamento de duas retas;

- visualmente, o ponto é sobreposto ao traçada da reta;

- assinalar muitos pontos em uma reta, faz aparecer uma graduação com marcas cada vez mais próximas; 
- há uma diferença importante entre a figura de um ponto e a noção geométrica do ponto. Esta noção é lembrada sem jamais ser definida. Foi evitada esta noção porque toda descrição oscila entre duas representações heterogêneas: uma do ponto material, marcando uma posição e a outra do limite de um processo em si mesmo ilimitado de redução e de desaparecimento do ponto material. (HEATH, 1956, p. 156-158). A primeira representação é atomista, a segunda dinâmica (no sentido operatório) e foge a toda representação figurativa (diferente da representação do traçado de uma reta). Existe, portanto, uma diferença semântica irredutível entre estas duas representações que procuramos implicitamente reunir para dar um sentido à noção de ponto.

Dessas cinco observações as seguintes são ressaltadas:

- existe congruência semântica entre a configuração "a reta com uma série de pontosposição sobre ela" e um subconjunto tão extenso quanto se queira de números racionais decimais;

- a propriedade de continuidade, diferente da densidade, não tem exatamente o mesmo sentido, se apresentadas a partir do traçado de uma trajetória, ou a partir da inacessibilidade de um limite na repetição de um processo de aproximação, mesmo que se postule a equivalência referencial entre estas duas representações. Portanto, é o que se quer, efetivamente, quando colocados os números reais em bijeção com a reta, recorrendo necessariamente, para tanto, à noção de ponto;

- uma representação atomista é a representação pertinente desde que se apresente a reta numérica (um conjunto infinito de pontos), assim como a indefinível noção de ponto no registro figurativo. A tentativa, nos anos 70 , de eliminar o registro figurativo do ensino da matemática, tinha a vantagem de contornar inconscientemente todos os obstáculos em que a não congruência semântica se revelava, ou pelo menos àqueles ligados à articulação entre o discurso natural e o registro figurativo. Isto foi um erro, do ponto de vista cognitivo, e mostrou-se ser um fracasso. Mas, sobre este exemplo, como em outros, esta tentativa histórica evidenciou o fato de que o recurso a diversos registros, ainda que necessário, implicava dificuldades.

- a não congruência semântica entre a reta e o conjunto de números reais é muito mais complexa do que os exemplos que serão mostrados a seguir, exemplos que veremos 
que bloqueiam os alunos. Como se alarmar, então, com a conclusão de uma enquete recente entre alunos de 17 e 18 anos:

... é insuficiente dar o exemplo da reta para fazer com que os alunos "sintam" as propriedades de R como a do "contínuo". De fato, $41 \%$ dos alunos viam a reta como um amontoado de pontos do tipo atômico; $32 \%$ que podem explicitar que R é uma bijeção com a reta,têm ainda esta visão preferencialmente atomista de reta. (ROBINET, 1986, p. 385).

Nenhum professor ficará chocado com este resultado. No entanto, outra questão proposta é surpreendente: "se engrossarmos com o microscópio eletrônico (ou com um computador) a reta, o que se obterá como desenho “último" (questão proposta também para o caso da parábola). Robinet (1986, p. 381), autor da enquete, precisa que esta questão foi colocada para tentar aprofundar o sentido de uma resposta geométrica à primeira questão (Como você representa os números reais? Se você tem uma imagem, represente-a).

A formulação da questão centra, muito explicitamente, sobre o registro figurativo e, mais particularmente, sobre a composição do suporte material do traçado da reta: espera-se, deste modo, um deslocamento da imagem perceptiva da reta como um traçado para uma outra imagem perceptiva simplesmente possível (uma vez que podem ser obtidos com um aparelho que não está à mão para verificação), o da reta como conjunto de pontos. Mas esta questão, ou qualquer outra proposição de ensino que explora esta utilização de registro figurativo, não é uma armadilha? Não somente ela apela para uma interpretação do tipo atomista, mas de fato ela tem pouca a ver com a imagem mental correta da reta dos reais, uma vez que se corre o risco de "misturar entre a imagem mental e a imagem perceptiva" ou "entre o modelo matemático e o modelo físico". (ROBINET, 1986, p. 382). Por esta observação, que leva a entender que a imagem mental se opõe, de certo modo, à imagem perceptiva, não reconhece a diferença semântica entre a reta geométrica, na qual dois pontos são suficientes para definí-la e que é representada por um traçado contínuo, e o conjunto dos reais? Não é sobre esta diferença que o ensino deveria prioritariamente centrar-se no lugar de postular a sua redução ao fato único de que a reta numérica é definida pela equivalência referencial?

Uma abordagem inteiramente diferente que constroi um circunferência ponto por ponto, é aquela que constroi a circunferência a partir do traçado de uma infinidade de retângulos, que tem um vértice em comum e as diagonais com os mesmos comprimentos, dando aos alunos a ocasião de começar a superar a não congruência semântica entre a continuidade de uma reta ou de uma curva e de sua interpretação como "conjunto de pontos". 
Pluvinage, Rauscher e Soumoy (1985) concluem, assim, as observações feitas a propósito desta atividade, realizada por alunos de 11 e 12 anos:

...será excessivo falar de revelação para alguns? Talvez não, se tentarmos imaginar o espanto em ver surgir uma figura que não desenhamos: traçam-se segmentos de retas e eis que surge uma circunferência como um conjunto de pontos (no entanto, dizer "uma circunferência é um conjunto de pontos..." jamais suscitou um mínimo gesto de admiração...). (p. 33).

Observa-se que, nesta atividade, a continuidade perceptiva e geométrica da reta surge da figura de um conjunto de pontos: não existe alguma operação que evoque a decomposição da continuidade em pontos ou a individualização possível de um destes pontos qualquer como limite de intervalos encaixantes cada vez menores. Além disso, a significação da continuidade perceptiva não se encontra associada ao movimento de um traçado.

\section{III.2. A não congruência semântica em enunciados de problemas}

O segundo exemplo vai nos aproximar das situações estudadas em experiências psicológicas. Tomamos aqui os resultados registrados por Koleza (1987) sobre problemas de proporcionalidade.

A partir de um enunciado tão simples como "eu paguei 51 francos por $6 \mathrm{~kg}$ de laranjas", duas questões são possíveis:

1 - Qual quantidade de laranjas terei com 85 francos?

2 - Quanto deverei pagar por $4 \mathrm{~kg}$ de laranjas?

A primeira questão é congruente ao enunciado. Ela remete diretamente à utilização do operador "função": p (kg) custam q (francos), pragmaticamente pressuposto pelo enunciado. A segunda questão, por outro lado, não é congruente ao enunciado. Ela exige uma inversão do operador "função". (KOLEZA, 1987, p. 69, 70). O simples fato de propor a segunda questão no lugar da primeira faz cair o percentual de acertos de $85 \%$ para 61\%. (KOLEZA, 1987, p. 131).

Quando o enunciado não impõe pragmaticamente algum operador (como, por exemplo, no enunciado "Um carro consumiu 28 litros de gasolina em 350 quilômetros"), os alunos que acertam escolhem, em sua grande maioria, o procedimento que torna o enunciado congruente com a questão. Assim, sendo colocadas as questões:

- Quanto o carro consumiu em $100 \mathrm{~km}$ ? 
- Qual distância que o carro pode percorrer se seu reservatório contém 42 litros?

Para responder a primeira questão, os alunos calcularam: $28 \ell \div 350 \mathrm{~km}=0,08 \ell / \mathrm{km}$.

Para responder esta segunda questão, que vinha logo em seguida da primeira, os alunos fizeram o cálculo: $350 \mathrm{~km} \div 28 \ell=12,5 \mathrm{~km} / \ell$. (KOLEZA, 1987, p.135, 136).

Tudo isto pode ser esquematizado com a situação mais concreta de uma receita de cozinha (KOLEZA, 1987, p. 123):

$\begin{array}{lllc}\text { enunciado } & \text { para } 4 \text { pessoas } & \rightarrow & 150 \mathrm{~g} \\ \text { questão congruente } & \text { para } 6 \text { pessoas } & \rightarrow & ? \\ \text { questão não congruente } & \text { para } ? \text { pessoas } & \leftarrow & 225 \mathrm{~g}\end{array}$

A oposição, no sentido das flechas, indica uma diferença de codificação para as sequências internas totalmente análogas à variação do ponto de referência, do qual foi apresentada a importância anteriormente, quando da comparação entre imagem e frase. Tem-se aqui o mesmo fenômeno cognitivo. O interesse deste exemplo, em relação ao precedente, é que ele mostra a não congruência semântica como uma fonte de dificuldades, independente do conteúdo matemático: uma atividade matemática pode ser bem sucedida se a sua apresentação e seu desenvolvimento não exigir alguma transformação entre as expressões de formulações ou de representações congruentes e, a mesma tarefa matemática dada com uma variante que implique manipulação de dados não congruentes, pode conduzir ao insucesso. Este aspecto é particularmente importante para a heurística de problemas de geometria e no despertar do desenvolvimento do raciocínio neste domínio ${ }^{5}$, que será apresentado a seguir.

\section{III.3. A não congruência entre frase e fórmula}

A passagem de um enunciado do discurso natural para uma expressão escrita simbolicamente com variáveis, símbolos de relação ou operação, constitui, para muitos alunos, um abismo dificilmente transponível. A utilização de equações do $1^{\circ}$ grau para resolver problemas é o lugar tradicional e sempre atual em que os professores se mostram de um modo espetacular, em não articular o registro da expressão discursiva com o registro da escrita simbólica.

\footnotetext{
${ }^{5}$ N. do T. Duval refere-se ao artigo DUVAL (1988) publicado no mesmo volume da revista. Este artigo está traduzido e disponibilizado na REVEMAT do primeiro semestre de 2012.
} 
Os manuais escolares antigos já consagravam todo um capítulo sobre "os problemas do $1^{\circ}$ grau" (BOREL e MONTEL, 1922) ou sobre "os problemas de álgebra" (LEBOSSÉ e HEMERY, 1951). Em relação a esta atividade complexa de utilização de equações do primeiro grau, está ressaltado o efeito do fenômeno da não congruência semântica; o problema seguinte servirá de exemplo:

Um homem tem 23 anos a mais do que seu filho, 31 anos a menos do que seu pai.

A soma da idade das três pessoas é 119 anos. Calcular as idades.

Designando por $\mathrm{x}$ a idade do pai e por $\mathrm{y}$ a idade do filho, podemos escrever a primeira equação de dois modos diferentes:

$\mathrm{x}-23=\mathrm{y}, \quad$ quer dizer, $\quad$ a idade do pai menos 23 é igual a idade do filho.

$\mathrm{x}=\mathrm{y}+23, \quad$ quer dizer, $\quad$ a idade do pai é igual a idade do filho mais 23.

Observa-se, de imediato, que as paráfrases das duas equações não são congruentes com a frase do enunciado: um pai tem 23 anos a mais do que seu filho. No entanto, a equação $\mathrm{x}+23=\mathrm{y}$ é semanticamente congruente com esta frase, mas não referencialmente congruente. Em razão da congruência, esta equação tem tudo para se impor como a descrição algébrica evidente da frase.

Em um trabalho antigo de atividades, muito mais simples do que a utilização de equações do primeiro grau, se pode observar o peso do fenômeno da não congruência. (DUVAL, 1971). O trabalho consistia em dar à escrita simbólica correspondente, a expressão discursiva de uma operação sobre números e, inversamente, parafrasear escritas simbólicas que expressavam também uma operação entre números. Para a expressão "a soma de dois produtos de dois inteiros, todos inteiros sendo diferentes", 90\% dos alunos de 13 ou 14 anos de idade transcreviam corretamente "a.b + c.d". Mas, somente $48 \%$ acertavam escrevendo "a.b + a.c" para a expressão "a soma dos produtos de um inteiro com dois outros inteiros". No primeiro caso há congruência semântica, uma vez que os dois produtos, simetricamente distribuídos em torno do símbolo da soma, são explicitamente mencionados na frase: outras observações mostram, de fato, que toda fórmula que se organiza simetricamente por um lado e de outro 
lado por um símbolo de relação (ou de operação) central é melhor compreendida pelos alunos do que os outros tipos de fórmula. No segundo caso, em compensação, não há mais congruência, uma vez que os dois produtos simetricamente distribuídos em torno do símbolo da soma não são mais explicitamente mencionados pela expressão discursiva.

Sem mais delongas sobre a articulação entre o registro da expressão discursiva e o registro da escrita simbólica, há que se terminar com uma anedota que François Pluvinage conta. Numa sessão de trabalho para a redação de um manual, um dos participantes faz a proposição seguinte:

\section{Se duas frações têm o mesmo denominador então elas se ordenam conforme os numeradores.}

Em outros termos: Se $a<b$ então $a / k<b / k$

Um outro participante recusa a expressão "Em outros termos" e propõe trocar esta expressão por "deste modo", "de onde", uma vez que o segundo enunciado não é uma simples transposição do primeiro: o primeiro participante acentuava a equivalência referencial, enquanto que o segundo era sensível a não congruência semântica das duas expressões.

\section{III - Congruência e funcionamento cognitivo do pensamento}

Diferentemente do discurso em linguagem natural, o discurso em matemática desenvolve-se principalmente por substituição e não por adjunção ou acumulação. (DUVAL, 1986, p. $45,46,52)$. É o que confere a todo desenvolvimento matemático uma ordem linear mais estrita do que a do desenvolvimento de um texto, em comum, em uma língua comum. A cada passo do desenvolvimento do raciocínio, do cálculo ou de um procedimento de resolução, a nova expressão não vem completar ou enriquecer as expressões anteriores e os dados iniciais, como em um texto descritivo, em um texto de história ou de uma discussão. Esta nova expressão vem, ao contrário, substituir a expressão do passo anterior, em virtude das definições, dos axiomas, dos teoremas e das tabelas de operações e de tantas regras de substituição, para que o pensamento progrida a partir dos dados iniciais: em um desenvolvimento onde se opera por substituição, a aproximação de duas expressões distantes não têm sentido. No entanto, em um texto que funciona por acumulação de informações, as precisões, a aproximação de duas frases distantes podem permitir que se encontre a coerência 
do discurso desenvolvido. (DUVAL, 1986, p. 80-86). A substitutividade é uma característica fundamental do funcionamento cognitivo do pensamento matemático e, é relativamente a esta substitutividade que os fenômenos de congruência semântica e não congruência semântica são importantes.

Para mostrar, por exemplo, que a soma dos ângulos de um triângulo equivale a $180^{\circ}$, traça-se, por um dos vértices, a paralela ao lado oposto:

Figura 2: esquema que mostra um processo de demonstração da soma dos ângulos internos de um triângulo.

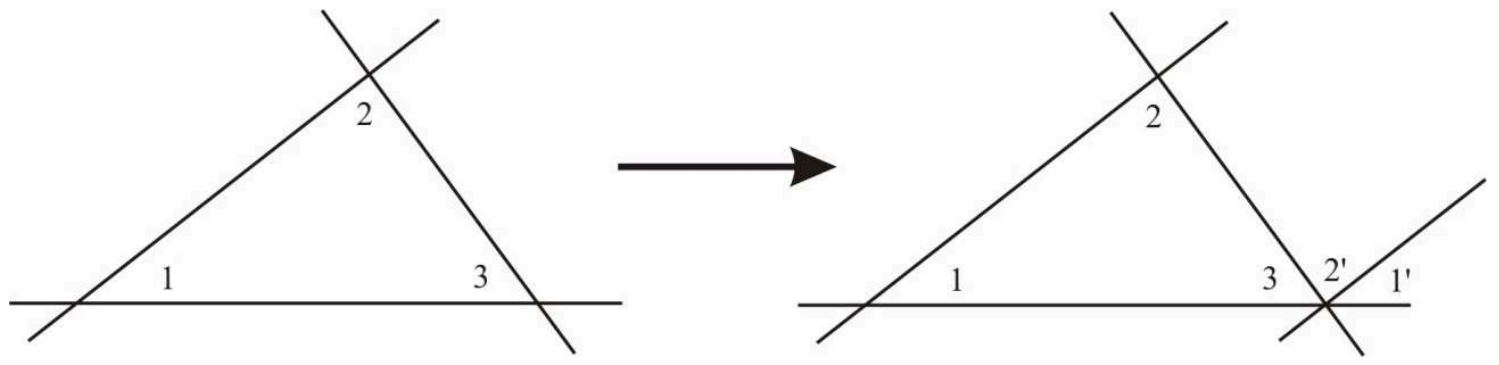

Este ato pressupõe que se veja uma reta como um ângulo de $\mathbf{1 8 0}^{\circ}$, quer dizer, que se possa substituir, indiferentemente, uma representação pela outra que são semanticamente diferentes. No entanto, figurativamente, um ângulo é uma "quina" ou dois segmentos partindo de um mesmo ponto: para ver uma reta, como um ângulo de $180^{\circ}$, é preciso adicionar outra reta concorrente. A noção de reta e a noção de ângulo plano não pertencem a mesma rede semântica de sentido associativo interno.

Um trabalho específico, favorecendo uma conscientização da equivalência referencial é, portanto, necessária. E, diga-se de passagem, para o desenvolvimento desta demonstração, elementar, a única substituição que não é congruente. No entanto, este aspecto, em uma fase de aprendizagem ou de pesquisa, poderá ser decisivo.

A utilização de fórmulas muito simples exige também a atividade de substituição. Já possível de ser observado com alunos de seconde ${ }^{6}$, dificuldades na utilização da fórmula $t=d / v$ na resolução do problema seguinte:

\footnotetext{
${ }^{6}$ No ensino básico francês, seconde corresponde ao $10^{\circ}$ ano de escolaridade, aproximadamente, à primeira série do ensino médio no Brasil.
} 
um ciclista percorre certa distância com a velocidade de $18,4 \mathrm{~km}$ por hora. Calcular esta distância, sabendo-se que ele ganhou um quarto de hora rodando a uma velocidade de $20 \mathrm{~km}$ por hora?

Alguns alunos colocaram $\mathrm{t} 1$ - $\mathrm{t} 2=1 / 4$, mas se recusavam a substituir $\mathrm{t} 1$ e $\mathrm{t} 2$ por $\mathrm{d} / 18,4 \mathrm{e} \mathrm{d} / 20$, respectivamente, mesmo tendo a fórmula à vista. Os dois membros não eram formalmente congruentes, uma vez que de um lado temos um símbolo único e de outro uma relação: apesar da igualdade escrita, d/v não significava para eles o tempo e, deste modo, não podia ser substituído pelo símbolo t, colocado como variável tempo.

A congruência e não congruência semântica têm papel importante na atividade de substituição, seja ela uma atividade inter ou intra-registro. Isto explica porque a coerência de um texto matemático ou de um outro tipo de texto não matemático seja tão dificilmente acessível para a maioria dos alunos (ao menos até 16 ou 17 anos de idade, ou acima desta idade em nível de estudo básico em fileira não científica). Isto mostra que, o que foi chamado de "jogo de quadros" por Douady (1984), constitui um objetivo, mas pode se defrontar com numerosos obstáculos, devidos a não congruência semântica. A situação em que foi didaticamente apresentada como exemplar, era uma situação na qual a substituição interregistro e os tratamentos intra-registro não se deparam com alguma dificuldade de não congruência: trata-se, fundamentalmente, de um fracionamento homogêneo de retângulos e quadrados e de codificação numérica de suas diferentes contagens, segundo a relação parte/todo. A definição de "quadro" proposto é estranha a toda tomada de consciência de eventuais diferenças semânticas:

um quadro é formado por objetos matemáticos, pelas relações que eles têm entre eles, pelas diferentes formulações e também pelas imagens mentais que são associadas a estes objetos. (DOUADY, 1985, p. 40).

O autor esclarece que mudar de quadro é:

- produzir diferentes formulações para um problema, estas diferentes formulações não sendo forçosamente semelhantes (quer dizer, não sendo forçosamente semanticamente congruentes);

- reconhecer em uma formulação, o emprego de instrumentos ou técnicas não utilizáveis em outra formulação.

Parece, então, que um quadro é muito mais vasto daquilo que chamamos de "registro" e que a mudança de quadro é que deve oferecer uma verdadeira compreensão matemática, pressupõe 
a superação das diferenças semânticas. Ora, é aqui, na superação das diferenças semânticas, que começa ou estanca, para um número razoável de alunos, a aprendizagem matemática.

\section{Conclusão}

Os signos, os símbolos e também todos os elementos icônicos, permitem construir uma representação que dão lugar às operações essenciais para o funcionamento do pensamento: a associação e a substituição.

A associação se faz de modo interno, segundo ligações contextuais e de pertinência a uma mesma rede semântica. Ela se faz também de modo externo, segundo regras de combinações de signos em expressões ou em configurações, regras que são próprias ao registro semiótico escolhido. Admiti-se, em geral, que a prática da associação externa reflita o jogo da associação interna: isto corresponde grosseiramente a nossa prática espontânea da palavra no discurso cotidiano. Nesta situação, a prática do discurso preenche uma função de troca e de comunicação e não uma função de tratamento e de transformação de informação. Para que um registro semiótico, incluindo a língua natural, possa responder a esta função de tratamento, é preciso introduzir condições semânticas de substituição por equivalência referencial. Na língua natural, isto se faz por meio do jogo das definições e de distinções. É desta maneira que a geometria euclidiana utiliza o registro do discurso natural e desenvolveu dentro das possibilidades da linguagem natural uma função de tratamento. A geometria euclidiana impôs, culturalmente, a imagem de um desenvolvimento do raciocínio more geometrico ligado ao discurso. Este desenvolvimento more geometrico funciona por substituição e não por acumulação ou por adjunção. Isto requer um salto em relação ao jogo de associação interna, o qual se faz segundo contextos reconhecidos e integrados pelo sujeito. Neste sentido, o desenvolvimento do raciocínio geométrico, que se exprime por meio das fontes da língua natural, difere radicalmente da argumentação. (GRIZE, 1982). A argumentação é um tipo de desenvolvimento que funciona, antes de mais nada, por acumulação ou por adjunção e não por substituição. A argumentação não pressupõe alguma definição, algum axioma para abrir um conjunto de equivalências referenciais. Quando, em uma argumentação, recorre-se às equivalências referenciais, é localmente por necessidades de "reduzir" uma afirmação adversa, real ou possível: o mais geralmente elas são sugeridas e não afirmadas (caso contrário elas podem ser recusadas). 
A lógica de uma argumentação diz respeito à apreensão da coerência global do discurso e não ao rigor do passo a passo, como em um desenvolvimento matemático. Esta diferença de funcionamento entre o desenvolvimento matemático (que privilegia a substituição e as equivalências referencias) e a argumentação (que guarda o princípio da acumulação e a congruência semântica própria ao discurso natural) é importante para que seja levada em conta na educação matemática. Em resumo, enquanto a associação externa dos signos ou dos símbolos fica subordinada ao jogo da associação interna, o indivíduo não pode se defrontar com problemas de congruência. Mas, desde que a atividade cognitiva exige um mínimo de tratamento (no plano da língua natural isto começa a aparecer com a prática da expressão escrita), a associação interna deve respeitar os percalços próprios ao registro do tratamento escolhido: os problemas de congruência semântica se tornam então primordiais, sobretudo na aprendizagem no final do nível primário, e nas quatro últimas séries do ensino fundamental.

Com os exemplos apresentados, privilegiamos o exame da congruência para o caso da substituição inter-registro, em detrimento da substituição intra-registro. A primeira é mais manifestamente independente do conteúdo matemático do que a segunda. Mas, isto não obriga que não haja sérios problemas de congruência semântica intra-registro ou que estes últimos estejam ligados às dificuldades matemáticas de conteúdo. Muito pelo contrário, no registro da escrita simbólica, escrita que permite por excelência o jogo da substituição de expressões ou de símbolos de um para outro, as dificuldades ligadas a não congruência podem ser importantes. Mas, os problemas de congruência ligados à substituição inter registro apresentam um interesse particular para o ensino geral de matemática, quer dizer, para o ensino de matemática até os 16 anos. Não somente eles constituem o primeiro muro a transpor para uma grande maioria de aluno, e isto não parece estar sendo seriamente levado em conta no ensino e na reflexão sobre o ensino; mais ainda, aprender a articular vários registros de representação da informação e aprender a diferenciar diversos tipos de funcionamento cognitivos poderão ser uma finalidade do ensino de matemática que se mostra interessante e útil aos não matemáticos.

Com apreciado neste trabalho, os problemas de congruência dão um novo acesso à questão da linguagem matemática. A linguagem natural não pode estar em oposição de modo simples e global à linguagem lógico-matemática e às representações figurais ou gráficas: a verdadeira fronteira, aquela que bloqueia muitos alunos, é a congruência e a não congruência semântica no jogo da substituição de uma expressão a outra, ou de uma representação a outra.

Os artigos Duval (2011) e Duval (2012) fornecem outros exemplos bastante detalhados. 


\section{Referências}

BOREL, E.; MONTEL, P. Algèbre. (3 $3^{\mathrm{a}}, 2^{\mathrm{a}}, 1^{\mathrm{a}}$ ) Paris: Armand Colin, 1922.

CLARK, H. H. Linguistic processus en deductive reasoning, in Psychological Review, 76, 9387-404, 1969.

CLARK, H. H., CHASE, W. G. On the process of comparing sentences against picture, in Cognitive Psychology, 3, p. 472-517, 1972.

DOUADY, R. Jeux de cadres e dialectique outil-objet dans l'enseignement des mathématiques. Thèse, Paris VII, 1984.

DOUADY, R. Interplay between differents settings, in proceedings of the ninth Int, Conf. for the Psichology of Mathematics Education, 1985.

DUCROT, O. Dire et ne pas dire. Paris: Hermam, 1972.

DUVAL, R. Gráficos e equações: a articulação de dois registros. 122. REVEMAT, v.6, n.2, Florianópolis: UFSC/MTM/PPGECT, 2011.

DUVAL, R. Abordagem cognitiva de problemas de geometria em termos de congruência. REVEMAT, v.7, n.1. Florianópolis: UFSC/MTM/PPGECT, 2012.

DUVAL, R. Lecture et Compréhension des textes, IREM de Strasbourg, 1986.

DUVAL, R. La compréhension du langage mathématique par un enfant de 4ème, in Langage mathématique et formalization, Colloque Inter-IREM, IREM de Bordeaux, 1971

GRIZE, J. B. De la logique à l'argumentation. Genève: Droz, 1982.

FREGE, G. Écrits logiques et philosophiques. Trad. Imbert. Paris: Seuil 1971.

HEATH, T. L. The thirteen Books of Euclid's Elements. v.1, NY: Donner, 1956.

KOLEZA-ADAM, E. Décalages cognitifs dans les problèmes de proportionnalité. Thèse, Strasbourg, 1987.

LEBOSSÉ, C. HEMERY, C. Algèbre, Arithmétique e Geométrie (4ème). Paris: Nathan, 1951.

PLUVINAGE, F.; RAUSCHER, J. -C.; SOUMOY, C. Rapport sur l'expérimentation "pédagogie différencie" conduite en mathématique au Collège d'Ostwald en 1984-85. IREM de Strasbourg, 1985.

ROBINET, J. Les Réels, quels modèles en ont les élèves? in Educational Studies in Mathematics, 17, p. 359-356, 1986.

QUINE, W. V. O. Le mot et la chose. Trad. Dopp, Gochet. Paris: Flammarion, 1977. 